\title{
New association for health humanities coming
} in 2018

- Cite as: CMAJ 2017 December 11;189:E1535. doi: 10.1503/cmaj.109-5532

Posted on cmajnews.com on Nov. 20, 2017.

$\mathbf{N}$ early three decades after the creation of the first humanities program at a Canadian medical school, the new Canadian Association for Health Humanities (CAHH) will launch in April 2018 at the Creating Space meeting in Halifax.

The new national association will promote the development of the health humanities in Canada through the Creating Space conference, regional meetings, a website and listserv, social media, and the literary journal Ars Medica.

The timing is right, says Dr. Allan Peterkin, a cofounder of the association and head of the Health, Arts and Humanities program at the University of Toronto.

Peterkin notes that when he helped launch the Creating Space health humanities conference in 2010, "most medical schools didn't have identifiable humanities divisions or departments, or even any kind of formal representations in the curriculum." Now, every medical school in Canada has both mandatory and elective humanities courses.

Despite this progress, it's still a struggle to stake out space for the humanities in medical training and practice, he says. "We always have to justify it to deans and to funders."

The recent shift to patient-centered care has strengthened the case for health humanities training. More than ever, medical schools want to develop trainees' reflective capacity, critical thinking and narrative competence, Peterkin explains. "We've been seduced by evidence-based medicine, but narrative celebrates what's unique about people."

For example, "teaching students how to look at art helps them with non-verbal cues when they're talking to patients and

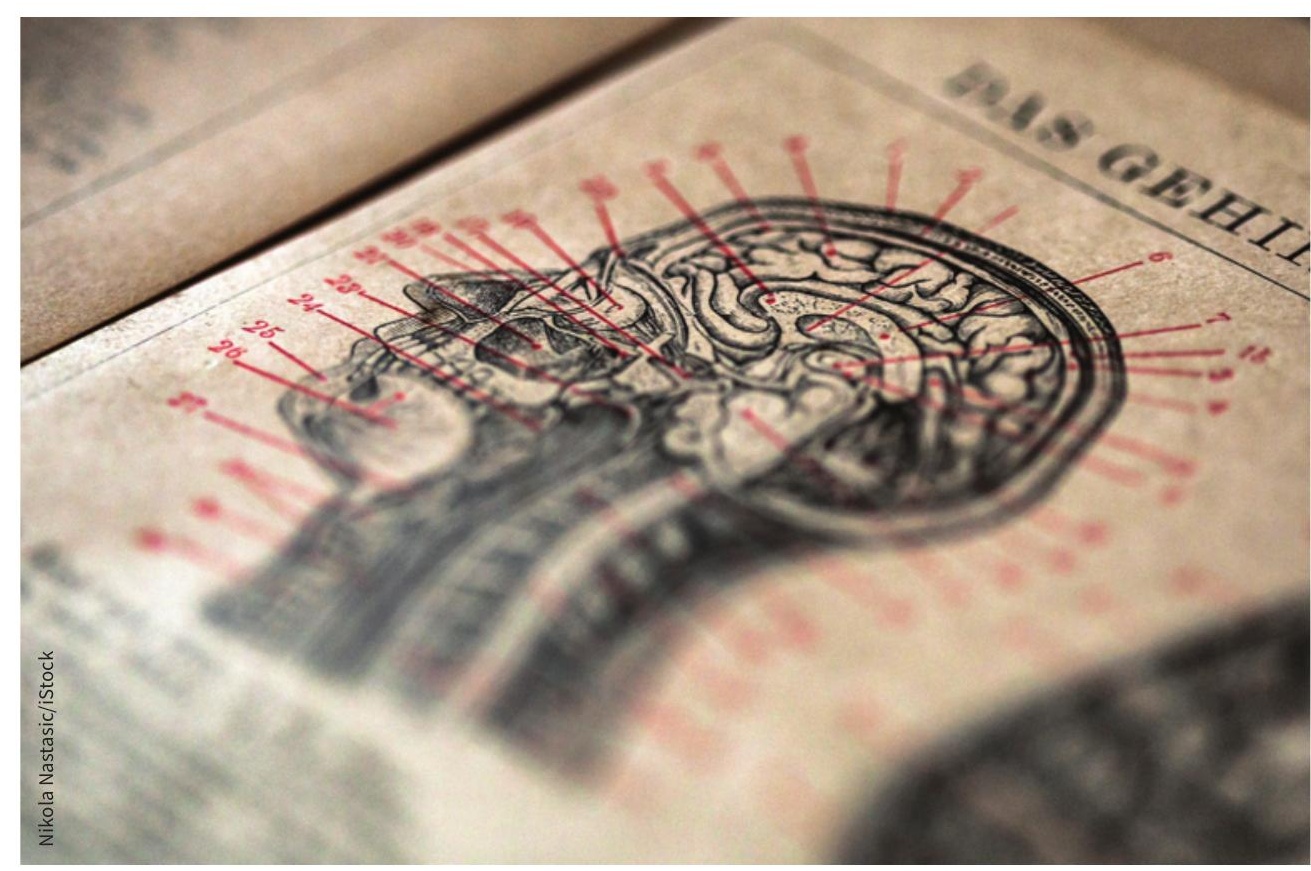

Canada's growing health humanities field will soon have a national association.

gives them an eye for detail that assists with diagnosis."

This is especially important as health care becomes more mechanized and focused on efficiency, says Pamela BrettMacLean, a CAHH cofounder and director of the Arts \& Humanities in Health \& Medicine program at the University of Alberta. The new association will create opportunities for leadership, networking and collaboration "to effect more sensitive, human-centred health care," she says.

High rates of burnout among health workers have also ignited interest in the humanities as a tool for processing the stress and tragedy encountered on the job, Peterkin adds. "We know that reflective practitioners take better care of their patients, but they also take better care of themselves."

CAHH will "continue the work of helping people to develop initiatives in their medical schools, advertising funding possibilities for research, mentoring the next generation of researchers, and lobbying for the growth of the humanities," he says. This will include pushing for medical schools to hire humanities scholars to teach courses "to get us to the next level of rigour."

Over the next six months, Creating Space organizers and participants can submit feedback on the association's website and draft constitution. There will be a vote to ratify the constitution and elect governing officers at the April meeting.

Lauren Vogel, CMAJ 